\title{
Cardiac orienting responses as a function of age ${ }^{1}$
}

FRANCES K. GRAHAM, KATHLEEN M. BERG, W. KEITH BERG, JAN C. JACKSON, HELEN M. HATTON, ${ }^{2}$ and SUSAN R. KANTOWITZ, ${ }^{3}$ University of Wisconsin, Madison, Wis. 53706

Heart-rate changes, recorded from human Ss under conditions appropriate for eliciting orienting, were curvilinearly related to age and independent of differences in prestimulus heart rate. Deceleration was absent at birth, increased from 6 to 16 weeks, and lessened between 16 weeks and young adulthood.

The heart-rate (HR) response to simple sensory stimuli may distinguish between two generalized arousal systems that have different effects on behaviorally significant processes. Deceleration of HR has been associated with an orienting system facilitating stimulus reception and learning, while HR acceleration has been associated with a protective energizing system that inhibits stimulus reception and registration (Graham \& Clifton, 1966; Lacey, 1959). It is interesting, therefore, that newborn studies have typically found monophasic acceleration of $\mathrm{HR}$, while studies of infants a few months older have found decelerative components or a solely decelerative response (Graham \& Jackson, in press). Unfortunately, age differences have been confounded with differences in initial HR level, in sleep-wake state, and in the intensity and onset characteristics of stimulation.

The effect of initial level on HR response is well known. With increasing prestimulus levels, the response is increasingly negative, i.e., a smaller acceleration or a larger deceleration. Since HR levels are lower at birth than in the early months of infancy, the developmental increase in deceleration might be due to initial level, provided that initial level has the same effect at different ages.

There is also evidence that sleep-wake state and stimulus characteristics are important in determining which arousal system is activated. On theoretical grounds, it might be expected that an orienting system would be less easily elicited during sleep than during waking states and empirical findings are compatible with this expectation (Graham \& Jackson, in press). ${ }^{4}$ That intensity of stimulation is an important factor in determining directional characteristics of response has been recognized by many writers (e.g., Sokolov, 1963). While orienting to nonreinforcing nonsignal stimuli depends on stimuli being "novel," they must be low or moderate in intensity since any stimulus may evoke a protective reaction if it is sufficiently intense. Sudden onsets may also elicit a protective reaction, the startle reflex, if intensity reaches a sufficiently high level rapidly enough (Fleshler, 1965). This factor is especially relevant in studying infant response, since infants may have lower thresholds for startle (Landis \& Hunt, 1939).

To permit comparison of the HR response when state, stimulus intensity, and stimulus onset are constant and appropriate for eliciting orienting, data has been drawn from four unpublished studies that included five age groups (Berg, 1970; Berg, Berg, \& Graham5; Hatton, 1969; Jackson, Kantowitz, \& Graham, in press). Initial level effects are examined statistically.

\section{PROCEDURES AND RESULTS}

The four studies differed in several respects, as discussed below, but all presented, in free field, a $2-\mathrm{sec}, 1,000-\mathrm{Hz}$ tone of moderate intensity $(75 \mathrm{~dB}$ re 0.0002 microbar) and slow rise time (30 or $300 \mathrm{msec}$ ). Only the first two stimulus presentations, given to awake Ss, are considered. Average HR was calculated for each of $20 \mathrm{sec}$, from $1 \mathrm{sec}$ before through $19 \mathrm{sec}$ following stimulus onset. In all studies, pulses coincident with stimulus onset and with each $R$ wave of the electrocardiogram were recorded on magnetic tape. A Laboratory Instrument Computer read times between successive $R$ waves to the nearest count (992 microsec) and a $3600 \mathrm{CDC}$ computer transformed R-R intervals to $H R$ in bpm. Reliability of the response was examined at each age by (1) $t$ tests of the difference between $H R$ on the first second preceding stimulus onset and on each of the $19 \mathrm{sec}$ following onset, (2) analyses of the variance among the first $10 \mathrm{sec}$ and in the linear through quartic orthogonal components of trend across the first 10 sec. Error terms for evaluating trends were based on the variance in the respective trends of individual Ss. Analyses of trend variance were also used in other comparisons noted in the text.

The first study, using newborns 30 to $62 \mathrm{~h}$ old, included only four trials-two were no-stimulus control trials and two were presentations of the slowly rising 75-dB tone. Sequence of trial type was balanced across the 12 Ss. An E observed infant state and triggered stimulus onset at a minimum of $45 \mathrm{sec}$ between trials or as soon after as the infant was in a quiet awake state, i.e., with eyes open and no sign of distress. The $E$ did not know the sequence to which an infant was assigned and received a masking noise through earphones. Newborns have usually been studied in sleepy or drowsy states, and it is difficult to obtain a spontaneously awake sample even with a brief testing session. To obtain 12 infants, 30 were tested and at least 82 other infants, who were selected to meet criteria of normal birth and postnatal condition, did not meet the criterion of being awake when observed in the nursery.

Changes in HR to the tone presentations are shown in Fig. 1. There was no evidence of any reliable response, nor were there any significant differences between tone and control trials. This study failed to replicate an earlier awake newborn study, also described in Jackson et al (in press), which obtained very tenuous evidence of a small deceleration under less well-controlled conditions.

Experiments at other ages employed either two or three stimuli in addition to the 75-dB stimulus under consideration. The several types of stimuli were presented in blocks, randomly assigned or balanced across Ss. In a study of 6-and 12-week-old infants, the 75-dB tone and a more complex tone were each presented for 2 and for $18 \mathrm{sec}$. In a study of 16-week-old infants, onsets of the 75-dB tone and of a $50-\mathrm{dB}$ tone were slow or rapid. The fourth experiment, using undergraduates, presented 50, 75-, and $90-\mathrm{dB}$ tones. Stimuli were automatically triggered at intervals of 40 to $50 \mathrm{sec}$ in the 6- and 12 -week infant study, at 45 -sec intervals in

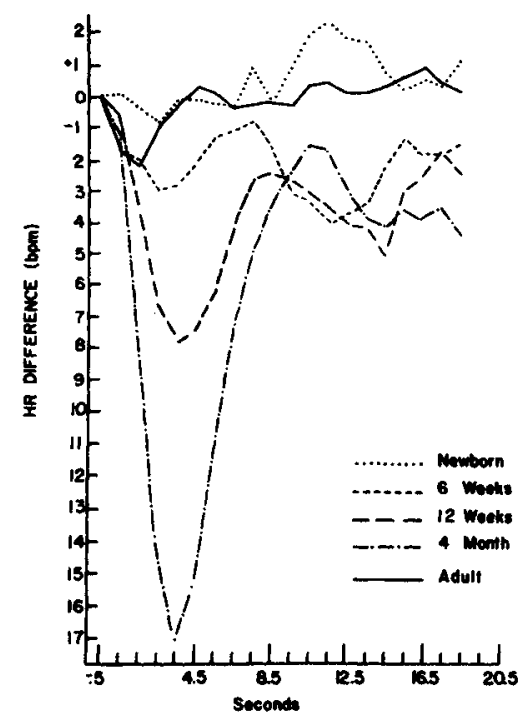

Fig. 1. Heart-rate changes during $19 \mathrm{sec}$ following a 75-dB, 1,000-Hz tone of gradual onset. 
the 16-week study, and at 45- to 75-sec intervals in the adult study.

In the older infant studies, an $\mathrm{O}$ seated beyond the infants' range of vision made observations, via a mirror, 5 to $10 \mathrm{sec}$ before each trial. There was a total of 24 infants tested at 6 and 12 weeks, half forming a longitudinal group tested at both ages. Since no practice effects were found, this distinction was ignored. It was less difficult to obtain awake infants at these ages than during the newborn period, but it was still a problem. Many infants fell asleep or began to cry before 16 trials had been completed. However, it was possible to select, at each age, 12 infants who were awake on either the first or second presentation of each of the four stimuli. Their response to the $2-\mathrm{sec}, 75-\mathrm{dB}$ tone is illustrated in Fig. 1. At 6 weeks, the response showed significant deceleration only during the second $10-\mathrm{sec}$ period, but by 12 weeks, response was significantly below prestimulus on Seconds 2 through 7 and had significant quadratic and quartic trends $(p<.01)$. This study also found significant differences in trend as a function of age and as a function of difference between the awake infants and similarly selected sleeping infants. As expected, awake infants decelerated and sleepy infants gave a largely accelerative response.

Twenty-four infants were also tested at 16 weeks. When Ss were ranked according to the number of trials on which they were awake, data could be conveniently divided at the median into alert and nonalert subgroups. All 12 infants above the median were awake on the first presentation and 10 were awake on the second presentation of the 75-dB, slowly rising tone. Their response, shown in Fig. 1, was a marked and immediate HR deceleration, highly significant $(\mathrm{p}<.001)$. In addition, there were significant differences in the expected direction between state subgroups and significant differences due to intensity and rise time effects.

Five adult studies from our laboratory have used the 2-sec, slowly rising, 75-dB tone (Berg \& Graham, in press). For the present age comparison, data are taken from the only study in which electroencephalographic recordings were available to confirm that $S s$ remained awake. Of the $24 \mathrm{Ss}$ in the experiment, two were drowsy on one of the two trials under consideration, and these trials were omitted. Average response, shown in Fig. 1, was a much smaller deceleration than the deceleration in infants of 12 and 16 weeks, but it was significantly below prestimulus on the first $2 \sec (p<.05)$ and showed a significant quartic trend across the first $10 \mathrm{sec}(\mathrm{p}<.05)$. Data from the other four adult studies suggests that the response is reasonably typical of adult response to this stimulus. Peak decelerations, in the average curves of the four studies, ranged from 1 to $4 \mathrm{bpm}$. DISCUSSION

Figure 1 illustrates a curvilinear relation between age and the magnitude of $H R$ deceleration. The age effect is clearly significant, as tested by analyses of the quadratic and quartic trends over $10 \mathrm{sec}$ and by the HR change during Second 3.5 $(p<.001)$. Since all Ss received the same stimulus and were in a waking state, these factors were not confounded with the age difference. However, initial HR level did vary with age. Mean prestimulus HR for the age groups in our studies were, in age order: $123.0,153.6,150.2,149.3,67.8$. If initial level affected response to the same degree at all ages, it could not account for the obtained results since deceleration should increase monotonically with initial level in the order: adult, newborn, 16, 12, and 6 weeks. Statistical analyses indicated that initial level did have a constant effect. There was no significant heterogeneity among the regressions of HR at Second 3.5 or among the regressions of trends, except that quartic trends differed at the .05 level. Analyses of covariance further confirmed the unimportance of initial level in explaining the age differences; with covariance, age effects remained significant at the .001 level for both quadratic trends and Second 3.5 change, and were significant at the .01 level for quartic trends. 6

The findings thus suggest that age differences in the HR decelerative response are not due to any of the several factors confounded with age in previous work Whether the differences are due to developmental change in peripheral or in central processes remains unanswered for the present. The problem is being approached, not by trying to rule out peripheral effects, but by determining whether or not the response is systematically related to variables that should affect a centrally controlled system. The evidence thus far is encouraging for the state and stimulus variables investigated. Sleepy states and rapid stimiulus onsets produce relatively accelerated responses in young infants as well as in adults (Graham \& Jackson, in press). There is relatively little information on the similarity of the intensity function but, in parallel studies of 16-week infants and young adults, partially reported here, differences between 50- and 75-dB tones were in the same direction in the two age groups (Berg et $\mathrm{al}^{5}$; Hatton, Berg, \& Graham, 1970). In brief, at all ages tested, HR showed an orderly relation to variables that should determine whether an orienting or a protective-energizing system is activated.

It seems reasonable to suggest, therefore, that the orienting system is, at best, not readily activated, or is a fragmentary system in the newborn, but that it develops rapidly over the first few months. This does not imply that newborns could not show HR deceleration to more optimal forms of stimulation, or that all components of an orienting system are absent at birth. An increase in orienting response during the early months of infancy may be related to the rapid neural development occurring during this period. The subsequent decrease is interesting in view of animal research showing a similar curvilinear relation between age and the effectiveness of sensory reinforcers. Kish (1966) suggests that accumulated experience with many stimuli may reduce the novelty effect of any given stimulus and thus reduce responsiveness in older age groups.

BERG, K. M. Heart rate and vasomotor responses as a function of stimulus duration and intensity. Unpublished MA thesis, University of Wisconsin, 1970.

BERG, W. K., \& GRAHAM, F. K. Reproducible effects of stimulus intensity on heart rate response curves (abstract). Psychophysiology, in press.

FLESHLER, M. Adequate acoustic stimuli for startle reaction in the rat. Journal of Comparative \& Physiological Psychology, 1965, 60, 200-207.

GRAHAM, F. K., \& CLIFTON, R. K. Heart-rate change as a component of the orienting response. Psychological Bulletin, 1966, 65, 305-320.

GRAHAM, F. K., \& JACKSON, J. C. Arousal systems and infant heart rate responses. In $\mathrm{L}$. P. Lippsitt and H. W. Reese (Eds.), Advances in child development and behavior. Vol. V. New York: Academic Press, in press.

HATTON, H. M. Developmental change in infant heart rate response during sleeping and waking states. Unpublished $\mathrm{PhD}$ thesis, University of Wisconsin, 1969.

HATTON, H. M., BERG, W. K., \& GRAHAM, F. $K$. Effects of acoustic rise time on heart rate response. Psychonomic Science, 1970, 19, 101-103.

JACKSON, J. C., KANTOWITZ, S. R., \& GRAHAM, F. K. Can newborns show cardiac orienting? Child Development, in press.

KISH, G. B. Studies of sensory reinforcement. In W. K. Honig (Ed.), Operant behavior: Areas of research and application. New York: Appleton, 1966. Pp. 109-159.

LACEY, J. I. Psychophysiological approaches to the evaluation of psychotherapeutic process and outcome. In E. A. Rubinstein and M. B. Parloff (Eds.), Research in psychotherapy. Washington, D.C: American Psychological Association, 1959. Pp. 160-208.

LANDIS, C., \& HUNT, W. A. The startle pattern. New York: Farrar \& Rinehart, 1939.

SOKOLOV, E. N. Perception and the conditioned reflex. New York: Macmillan, 1963.

NOTES

1. We thank nurses and staff of St. Mary's Hospital, Madison, Wisconsin, for their 
cooperation. Supported by NIH Grants HD01490, K5-MH-21762, and FR00249. J.C.J. is an NIH predoctoral fellow and K.M.B. and W.K.B. are NIH predoctoral trainees.

2. Present address: Children's Asthma Research Institute and Hospital, Denver, Colo. 80204.

3. Present address: Department of Child Development and Family Life, Purdue University, Lafayette, Ind. 47907.

4. Sokolov (1963) claimed that "orienting reflexes" could be "reinstated" during sleep, but the response he described better meets his criteria of a "defensive reflex" since it was nonhabituating and included cephalic vasoconstriction (p. 122).

5. Berg, K. M., Berg, W. K., \& Graham, F. K. Infant heart rate response as a function of stimulus and state. Unpublished manuscript, 1970

6. For computational convenience, equal numbers of $S s$ were obtained at each age by including only the first 12 adult Ss in the analysis of age effects.

\section{The effect on retention of successive recall trials before unlearning}

\author{
GERALD LAZAR, State University \\ College, New Paltz, N.Y. 12561
}

Successive recall trials (present or absent) after first list learning was factored against an unlearning condition (present or absent). While unlearning retarded retention, successive recall did not reliably counteract the unlearning effect.

Successive recall trials might be characterized as repetition without overt reinforcement. It is a procedure in which the stimulus members of paired associates are presented as cues for second-member recall and $S$ is given no information regarding the correctness of his responses, i.e., the response members are omitted. Two alternative hypotheses have recently been suggested about the effect of successive recall trials: (1) they lead to an increase of associative strength (Richardson \& Gropper, 1964), and (2) they affect availability rather than associative strength (Lazar, 1969). In most retention studies, these hypotheses would lead to the same prediction. They can, however, be differentiated in an unlearning situation. In this experiment, successive recall trials follow first list (A-B) learning. If successive recall trials strengthen $A-B$ associations, then the unlearning effect ought to be reduced and groups with successive recall following A-3 learning would have better $A \cdot B$ recall than control groups. However, if successive recall merely makes A-B associations more available, then the learned associations should be more easily elicited during A-C learning, thereby resulting in more unlearning (Postman, 1965). Thus, within the unlearning paradigm the availability hypothesis predicts less A-B recall, while the associative strengthening hypothesis, in conjunction with the elicitation hypothesis of unlearning, predicts greater A-B recall for groups receiving successive recall trials after A-B learning and prior to A-C acquisition.

\section{DESIGN}

The design of the experiment was a 2 by 2 factorial varying the presence or absence of successive recall trials after A-B learning and the presence or absence of an unlearning task (A-C vs D-C) after recall.

\section{MATERIALS}

Three lists of 10 paired associates were constructed. The A-B list was constructed using high-frequency $(\mathrm{A}, \mathrm{AA})$ words from the Thorndike-Lorge (1944) word count. They were paired randomly with the restrictions that (1) there be no obvious associations between members of a pair, and (2) that no members of a pair have the same initial letter. The same restrictions were observed in the construction of the remaining lists. The A-C list was composed of the same stimulus items as the A-B list. The response members were either the first or second associate to 10 of the Cohen, Bousfield, \& Whitmarsh (1957) category names. The D-C list was composed of stimulus members selected from the Thorndike-Lorge word count (A, AA) and the response items were the same as those appearing in the A-C list.

\section{TRAINING}

The alternating training-test method was used. There were three orders of training and testing to minimize serial learning. Material was presented with a slide projector at a $2.5-\mathrm{sec}$ rate. A 4-sec interval separated training and test phases, and six training and test trials were given on each list. After A-B acquisition, the groups receiving successive recall trials were given six trials of stimulus presentation at the same rate as in training and were asked to recall the responses aloud. They were given no information about the correctness of their responses. The stimulus items for the successive recall trials appeared in the same three orders used in training. The groups without successive recall after training were given about $3 \mathrm{~min}$ of a filler activity consisting of sorting playing cards into suits, naming aloud each card as it was sorted. After successive recall trials or the filler activity, all groups received six trials of training and testing on either the A-C or the D.C list. The retention test immediately followed the last test trial of second-list acquisition.

\section{RECALL}

A modified modified-free-recall test was used to measure retention. Ss were given a sheet of paper on which the $A$ items were printed in a column. To the right of each $A$ item, two blank lines were printed. Ss were instructed to write the words that had been paired with the $A$ iterns. They were not asked to indicate what lists the items came from. They were allowed to fill in the items in any order and they were given unlimited time for the task.

\section{SUBJECTS}

The Ss were 60 experimentally naive undergraduate volunteers from general psychology classes who were given extra course credit for taking part in the experiment. They were assigned randomly to each of the four treatments in the order that they appeared in the laboratory, except for the restriction that there be 15 Ss in each condition.

\section{RESULTS}

All analyses were based on the number of correct A-B responses. The mean correct responses given on the last test trial of acquisition and on recall, and their difference scores, are displayed in Table 1. A two-way analysis of variance on the number of correct responses given on the last $A \cdot B$ test trial yielded an $F$ of 7.43 $(\mathrm{df}=1 / 56)$ on the unlearning factor, which was barely significant at the .05 level. The $F$ for successive recall and the $F$ for the Successive Recall by Unlearning interaction were both less than 1. An Fmax test for heterogeneity of variance yielded 8.19 , which was significant beyond the .01 level. Therefore, it was decided to analyze the recall data as difference scores between the number of correct responses on the last trial of testing during A-B acquisition and on MMFR. A square-root transformation was performed on these difference scores. 